\title{
RESEARCH
}

Open Access

\section{Partial reduction of amyloid $\beta$ production by $\beta$-secretase inhibitors does not decrease synaptic transmission}

Tugce Munise Satir ${ }^{1 \dagger}$, Lotta Agholme ${ }^{1 *+}\left(\mathbb{D}\right.$, Anna Karlsson², Mattias Karlsson², Paul Karila², Sebastian Illes ${ }^{2}$, Petra Bergström ${ }^{1}$ and Henrik Zetterberg ${ }^{3,4,5,6}$

\begin{abstract}
Background: Alzheimer's disease (AD) is the most common form of age-related neurodegenerative diseases. Cerebral deposition of $A \beta$ peptides, especially $A \beta 42$, is considered the major neuropathological hallmark of $A D$ and the putative cause of $A D$-related neurotoxicity. $A \beta$ peptides are produced by sequential proteolytic processing of APP, with $\beta$-secretase (BACE) being the initiating enzyme. Therefore, BACE has been considered an attractive therapeutic target in AD research and several BACE inhibitors have been tested in clinical trials, but so far, all have had negative outcomes or even led to worsening of cognitive function. AD can be triggered by A $\beta$ years before the first symptoms appear and one reason for the failures could be that the clinical trials were initiated too late in the disease process. Another possible explanation could be that BACE inhibition alters physiological APP processing in a manner that impairs synaptic function, causing cognitive deterioration.
\end{abstract}

Methods: The aim of this study was to investigate if partial BACE inhibition, mimicking the putative protective effect of the Icelandic mutation in the APP gene, could reduce A $\beta$ generation without affecting synaptic transmission. To investigate this, we used an optical electrophysiology platform, in which effects of compounds on synaptic transmission in cultured neurons can be monitored. We employed this method on primary cortical rat neuronal cultures treated with three different BACE inhibitors (BACE inhibitor IV, LY2886721, and lanabecestat) and monitored $A \beta$ secretion into the cell media.

Results: We found that all three BACE inhibitors tested decreased synaptic transmission at concentrations leading to significantly reduced $A \beta$ secretion. However, low-dose BACE inhibition, resulting in less than a $50 \%$ decrease in $A \beta$ secretion, did not affect synaptic transmission for any of the inhibitors tested.

Conclusion: Our results indicate that $A \beta$ production can be reduced by up to $50 \%$, a level of reduction of relevance to the protective effect of the Icelandic mutation, without causing synaptic dysfunction. We therefore suggest that future clinical trials aimed at prevention of $A \beta$ build-up in the brain should aim for a moderate CNS exposure of BACE inhibitors to avoid side effects on synaptic function.

Keywords: BACE inhibition, Synaptic transmission, Alzheimer's disease, Amyloid beta, Beta-secretase

\footnotetext{
* Correspondence: lotta.agholme@gu.se

${ }^{\dagger}$ Tugce Munise Satir and Lotta Agholme contributed equally to this work. 'Institute of Neuroscience and Physiology, Department of Psychiatry and

Neurochemistry, the Sahlgrenska Academy at the University of Gothenburg, S-415 30 Gothenburg, Sweden

Full list of author information is available at the end of the article
}

C C The Author(s). 2020 Open Access This article is licensed under a Creative Commons Attribution 4.0 International License, which permits use, sharing, adaptation, distribution and reproduction in any medium or format, as long as you give appropriate credit to the original author(s) and the source, provide a link to the Creative Commons licence, and indicate if changes were made. The images or other third party material in this article are included in the article's Creative Commons licence, unless indicated otherwise in a credit line to the material. If material is not included in the article's Creative Commons licence and your intended use is not permitted by statutory regulation or exceeds the permitted use, you will need to obtain permission directly from the copyright holder. To view a copy of this licence, visit http://creativecommons.org/licenses/by/4.0/ The Creative Commons Public Domain Dedication waiver (http://creativecommons.org/publicdomain/zero/1.0/) applies to the data made available in this article, unless otherwise stated in a credit line to the data. 


\section{Background}

Alzheimer's disease (AD) is the most common agerelated form of dementia, and it is estimated that almost 50 million people are affected worldwide [1]. Until this day, there is no treatment available to stop or even slow down the disease process. Such treatments are urgently needed as the incidence is predicted to increase due to the aging population globally. Pathologically, AD is characterized by accumulation of amyloid $\beta(A \beta)$ in extracellular senile plaques and tau in intracellular fibrillary tangles in the brain. Although the exact cause(s) of AD is still a matter of debate, most data suggest that cerebral accumulation of aggregated $A \beta$ is triggering the disease process, with tau pathology being a downstream alteration $[2,3]$. Therefore, treatments aimed at decreasing $A \beta$ production or increasing $A \beta$ clearance from the brain have been thoroughly investigated for more than a decade.

$A \beta$ peptides are generated from the sequential cleavage of $\mathrm{A} \beta$ precursor protein (APP) by $\beta$ - and $\gamma$-secretases [4]. Therefore, a multitude of drug candidates targeted at either $\beta$ - or $\gamma$-secretase have been developed to treat $\mathrm{AD}$ [5]. $\gamma$-Secretase inhibitors and modulators were the first to be tested in clinical trials, but all the trials have had to be halted due to lack of efficacy or sometimes serious side effects [6]. $\gamma$-Secretase has many other biological substrates that could explain the negative effects and therefore the focus turned to $\beta$-secretase (BACE) inhibitors. There is a considerable amount of evidence regarding the involvement of BACE1 in AD pathogenesis. Increased protein levels and activity of BACE1 have been reported in the normal aging brain and to an even larger extent in the AD brain [7-9]. In addition, a mutation in $A P P$ resulting in increased BACE1 cleavage (called the Swedish mutation) results in increased $A \beta$ production and a familial form of AD (FAD) [10]. On the contrary, the so-called Icelandic mutation in APP [11], which alters one amino acid at the BACE1 cleavage site of APP, reducing the ability of BACE1 to cleave APP by about $30 \%$ [12], is strongly protective against AD. Therefore, a wide variety of small molecules inhibiting BACE was developed and brought to clinical trials. Again, although these inhibitors successfully reduce $A \beta$ production in both animals and humans [13, 14], they have been discontinued in phase II or III trials due to lack of efficacy and/or side effects (including cognitive decline) [14]. Whether these side effects are due to on- or off-target effects of the BACE1 inhibitors is not known. However, BACE1 is responsible for cleavage of other substrates as well, and knockout of BACE1 in mice caused both physiological and behavioral deficiencies [14]. These included increased astrogenesis, impaired axonal structure, impaired neuronal maturation and migration, impairments in long-term potentiation (LTP) and long-term depression, as well as cognitive and emotional memory deficiencies [14].

Although certain variants of $\mathrm{A} \beta$ peptides are considered toxic, they are endogenously produced by neurons [15] and have been suggested to be involved in neuronal development and differentiation, as well as neuronal function [16-19]. Therefore, a partial reduction of $A \beta$ instead of aiming for complete removal or high-grade inhibition could have better outcome. It is thus of great importance to investigate how a reduction in $A \beta$ by novel AD drugs affects synaptic function, before proceeding to clinical trials. In this study, we applied an established method to measure synaptic activity [20] to investigate if $\mathrm{BACE}$ inhibition could reduce $A \beta$ without affecting synaptic transmission. The optical electrophysiology platform has previously been used to investigate the effects on synaptic transmission of, e.g., mood disorder drugs, such as the N-methyl-d-aspartate (NMDA) receptor antagonist dizocilpine and the anticonvulsant NBQX, which is an antagonist at $\alpha$-amino-3-hydroxy-5methyl-4-isoxazolepropionic acid (AMPA) receptors [21]. Here, it was used to screen for effects on synaptic transmission following treatment with three BACE inhibitors: BACE inhibitor IV, LY2886721, and lanabecestat. BACE inhibitor IV has been shown to decrease A $\beta$ levels in cell-conditioned media [22], but has not been tested in clinical trials. LY2886721 is a selective BACE inhibitor, which does not affect the other aspartyl proteases and is known to decrease both brain amyloid deposition and cerebrospinal fluid (CSF) A $\beta$ levels [23]. It was the first BACE inhibitor to reach a phase II clinical trial, but the trial was halted due to liver toxicity [24]. Lanabecestat (also called AZD3293 or LY3314814) is a powerful BACE1 inhibitor, known to reduce $A \beta$ in CSF as well as to reduce $A \beta$ positron emission tomography (PET) imaging in the brain of both healthy individuals and AD patients [25]. Lanabecestat was tested in clinical trials, but was withdrawn due to lack of efficacy, and it has also been suggested to worsen memory [26].

All three BACE inhibitors act by binding to the active site of BACE1 and BACE2 and were chosen based on their activity on BACE1/2 or outcomes from the clinical trials. BACE inhibitor IV is more selective to BACE1 than BACE2 [27], but did not reach clinical trials. Both LY2886721 and lanabecestat have been tested clinically, in phase I/II and II/III trials respectively (ClinicalTrials.gov NCT01561430) [26]. They have been shown to inhibit BACE1 and BACE2 equally and the doses used in clinical trials were comparable, but the reported side effects differed. Therefore, we wanted to compare in vitro effects on synaptic transmission between these inhibitors.

We aimed to investigate if BACE inhibitors would affect synaptic transmission at inhibition levels causing clinically relevant $A \beta$ reduction and, if so, if $A \beta$ could be 
partially decreased through BACE inhibition, as observed in patients with the protective Icelandic mutation [11], without affecting synaptic transmission. We found that all BACE inhibitors investigated affected synaptic transmission negatively at high concentrations, but that reduced transmission as a result of BACE inhibition could not be explained solely by reduced $A \beta$ levels. Low-dose BACE inhibition resulting in moderate $A \beta$ reduction $(30-50 \%)$ did not affect synaptic transmission for any of the inhibitors tested.

\section{Materials and methods}

\section{Cell culturing and treatment}

Cortical neurons from E18 Sprague Dawley rats were obtained as described previously [28]. The cortical tissue was gently triturated with a sterile, silanized glass Pasteur pipette in Hibernate $\mathrm{E}$ to dissociate the tissue. The solution was left for $1 \mathrm{~min}$ to precipitate the nondissociated tissue, and the supernatant from each tube was then transferred and pooled in a 15-ml tube. After trituration, the cell suspension was spun down for $5 \mathrm{~min}$ at $250 \times g$ and the pellet was carefully re-suspended with the silanized Pasteur pipette. NBActiv4 with gentamycin sulfate $(10 \mu \mathrm{g} / \mathrm{ml})$ was added to the cell suspension, and cells were carefully triturated to dissociate cell aggregates. The cell suspension was strained on a $40-\mu \mathrm{M}$ pore diameter cell strainer to reduce the amount of larger pieces of tissue, and cells were counted using a Scepter cell counter. One hundred thousand cells/well were added per well in poly-D-lysine-coated 96-wells plates. The plates were incubated at $37^{\circ} \mathrm{C}, 5 \% \mathrm{CO}_{2}$, and $95 \%$ humidity for 14 days to allow for formation of synaptically connected neuronal networks.

On 10 days in vitro (DIV), cells were exposed to either the BACE inhibitors LY2886721 (S2156; Selleckchem), BACE inhibitor IV (565,788; Merck Millipore) or lanabecestat (S8193; Selleckchem), or the $\gamma$-secretase inhibitor LY411575 (S2714; Selleckchem), or the $\alpha$-secretase ADAM10 inhibitor GI254023X (also inhibiting MMP9 and MMP13) (S8660; Selleckchem), or a vehicle control (DMSO) for 4 days. All compounds were added at three concentrations: $0.04,0.3$, and $3 \mu \mathrm{M}$ final concentration. All procedures for experiments were performed in accordance with the ethical committee in Gothenburg (ethical permit 5.8.18-11305/2018) and followed the guidelines of the Swedish National Board for Laboratory Animals.

\section{Compound effects on $A \beta$ secretion}

Cell medium was collected and pooled from wells previous to stimulation, centrifuged at $400 \times g$ and stored at $80^{\circ} \mathrm{C}$ until further analysis. A $\beta$ concentrations in conditioned media were measured using the 4G8 A $\beta$ Triplex kit (Mesoscale Diagnostics, Rockville, MD) according to the manufacturer's instruction. Assay plates were analyzed using QuickPlex SQ 120 instrument and Discovery Workbench software (Meso Scale Discovery).

\section{Compound effects on synaptic transmission}

Four days after compound addition to the cortical cultures (14 days after seeding), electric field stimulation (EFS) experiments were performed on an optical electrophysiology platform (Cellectricon AB, Mölndal, Sweden) [20], where the effect of the compounds on synaptic transmission was investigated. Before the EFS experiments, a calcium indicator (Calcium 5, Molecular Devices, CA, USA) was added to the neuronal cultures for one hour. The cell plates were then inserted into the optical electrophysiology platform and an EFS protocol was subsequently applied. After 14 days, neurons in the cortical cultures were synaptically connected and the response to EFS was reproducibly transduced to areas distant from the stimulating electrodes. To enable quantification of changes in the synaptic signal caused by EFS, the fluorescence intensity from the calcium probe was simultaneously monitored in regions of interest (ROIs) distant to the stimulation electrodes. The measured signal was derived from neurons that were synaptically connected to the neurons stimulated by the electric field. Reference compound tetracaine was also included as a positive control on each plate and for normalization purposes (the effect of a high concentration of tetracaine fully blocks the synaptic calcium response and this response was set to $0 \%$ ). DMSO control wells were also present on each plate (same [DMSO] as in the drug-treated wells), and the resulting calcium response in the control wells was set to $100 \%$ during the normalization. To ensure consistency between preparations, the reference compound allopregnanolone (a positive allosteric GABAA modulator) was also present in concentration-response format. The effect of the compounds on the synaptically mediated increases in $\mathrm{Ca}^{2+}$ fluorescence on the optical electrophysiology platform [20] was then quantified: The normalized median value of the approximately 12 pulses that were captured during a 3-min EFS train $(0.33 \mathrm{~Hz})$ is presented. See Fig. 1 for example calcium fluorescence intensity traces for untreated control wells, tetracaine-treated wells, and LY2886721 from one of the two individual primary cortical cultures.

\section{Statistical analysis}

Mean values from separate experiments $(n)$ were compared using Student's two-tailed $t$ test. Statistical significance was defined as $p<0.05$. All statistical analyses were performed using GraphPad (Prism version 7.02 for Windows, GraphPad Software, La Jolla, CA, USA, www. graphpad.com). 


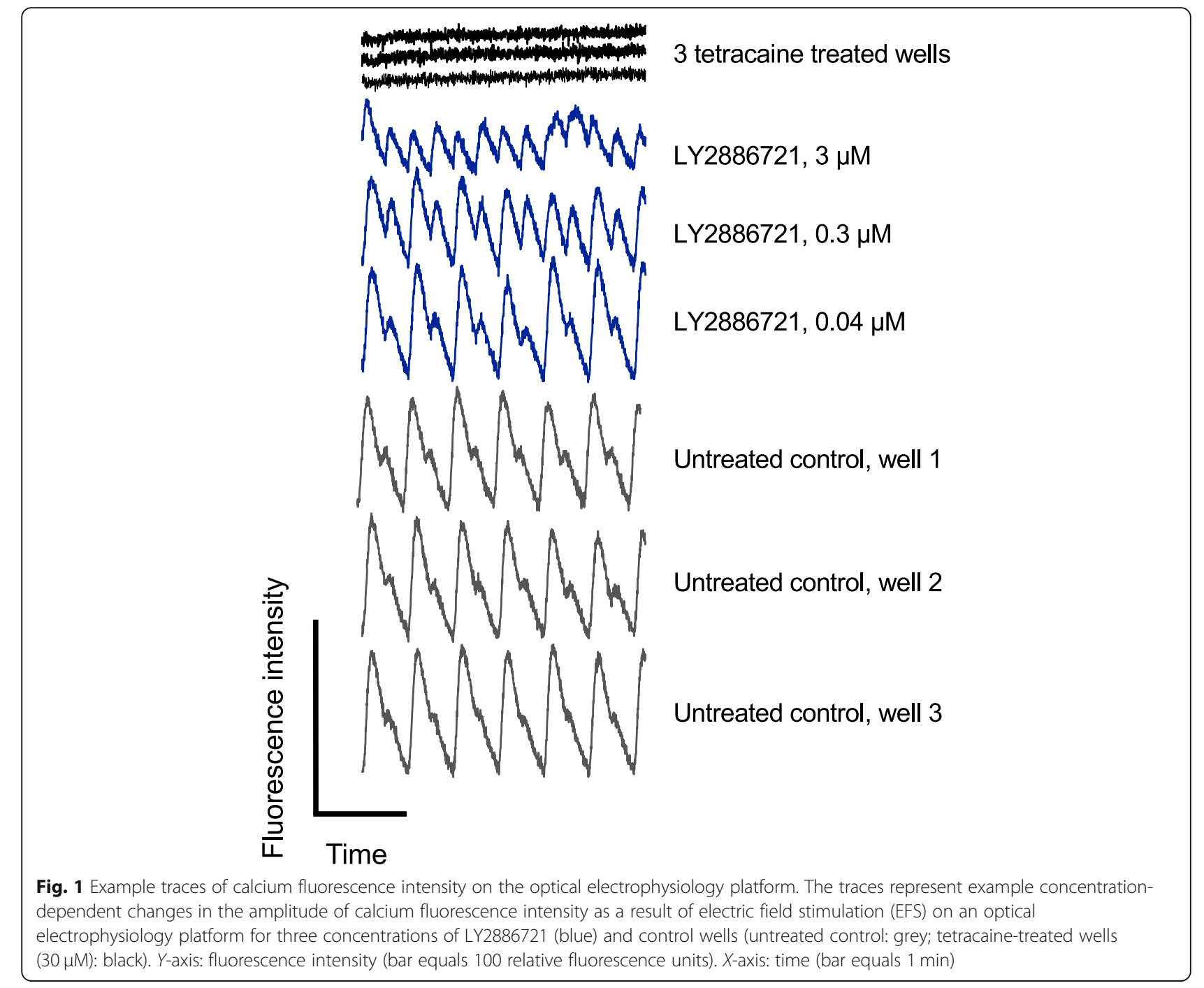

\section{Results}

The effect of BACE inhibitors on $A \beta$ secretion and synaptic transmission

To investigate the effect of the three different BACE inhibitors on synaptic transmission, we treated cortical rat neuronal cultures with the BACE inhibitors for 4 days and thereafter investigated $A \beta$ secretion and synaptic transmission. Based on previous publications, where low $\mu \mathrm{M}$ concentrations of the BACE inhibitors were used in vitro $[22,29]$, the concentrations were titrated down from 3 to $0.04 \mu \mathrm{M}$, aiming to induce partial BACE inhibition. Three micromolar resulted in high $A \beta$ reduction, similar to those observed in clinical trials [30]. Lanabecestat treatment significantly decreased secretion of both $A \beta 40$ (Fig. 2a (I)) and $A \beta 42$ (Fig. 2a (II)) with approximately $70 \%$ at all concentrations tested. Correspondingly, all three concentrations decreased synaptic transmission with approximately 14-18\% (Fig. 2a (III)).
Treatment with $0.04 \mu \mathrm{M}$ LY2886721 resulted in a trend towards decreased secretion of A 340 with $39 \%$, while $0.3 \mu \mathrm{M}$ significantly decreased $\mathrm{A} \beta 40$ with $53 \%$ and $3 \mu \mathrm{M}$ decreased A $\beta 40$ with 57\% (Fig. 2b (I)). LY2886721 treatment also showed a trend towards decreased secretion of $\mathrm{A} \beta 42$ with $37 \%$ at $0.04 \mu \mathrm{M}$ and with $43 \%$ at $0.3 \mu \mathrm{M}$ and significantly decreased $\mathrm{A} \beta 42$ with $57 \%$ at $3 \mu \mathrm{M}$ (Fig. 2b (II)). LY2886721 at $0.04 \mu \mathrm{M}$ and $0.3 \mu \mathrm{M}$ did not affect synaptic transmission, while $3-\mu \mathrm{M}$ LY2886721 treatment significantly decreased synaptic transmission with 39\% (Fig. 2b (III)).

BACE inhibitor IV treatment of primary neurons in culture significantly decreased secretion of $A \beta 40$ with $39 \%$ at $0.04 \mu \mathrm{M}$, with $62 \%$ at $0.3 \mu \mathrm{M}$ and with $65 \%$ at $3 \mu \mathrm{M}$ (Fig. 2c (I)). Similarly, BACE inhibitor IV significantly decreased secretion of $A \beta 42$ with $38 \%$ at $0.04 \mu \mathrm{M}$, with $58 \%$ at $0.3 \mu \mathrm{M}$ and with $61 \%$ at $3 \mu \mathrm{M}$ (Fig. $2 \mathrm{c}$ (II)). Investigation of synaptic transmission revealed that treatment with $0.04 \mu \mathrm{M}$ BACE inhibitor IV resulted in a 


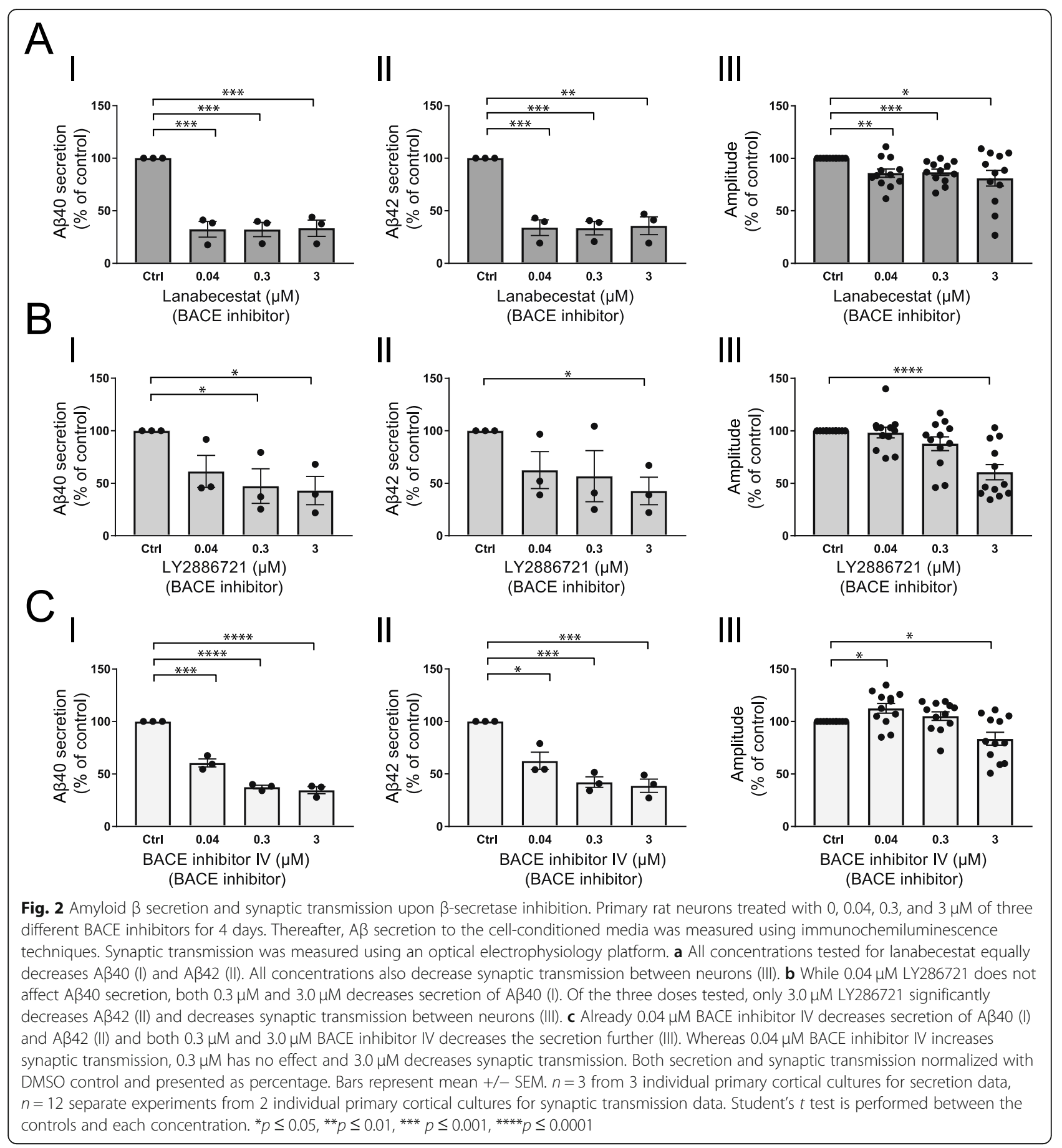

small but significant increase in synaptic transmission (13\%), while $0.3 \mu \mathrm{M}$ showed no affect and $3 \mu \mathrm{M}$ significantly decreased synaptic transmission with 16\% (Fig. 2c (III)).

\section{The effect of $\gamma$-secretase and $\alpha$-secretase inhibitors on} synaptic transmission and $A \beta$ secretion

To further test if synaptic transmission was related to inhibitor effects on $\mathrm{A} \beta$ secretion, we investigated inhibitors of other secretases involved in APP processing. The neurons were treated with one $\gamma$-secretase inhibitor (LY411575), expected to decrease both $A \beta 40$ and $A \beta 42$, and one $\alpha$-secretase inhibitor (the selective ADAM10 inhibitor GI254023X) that cleaves APP in the middle of the $A \beta$ sequence and is not expected to affect the production of $A \beta 40$ and $A \beta 42$ [4] as described above, before measuring synaptic transmission. As predicted, $\gamma$-secretase inhibition with LY411575 decreased A 340 secretion with about $85 \%$ at all concentrations tested (Fig. 3a (I)) and, 


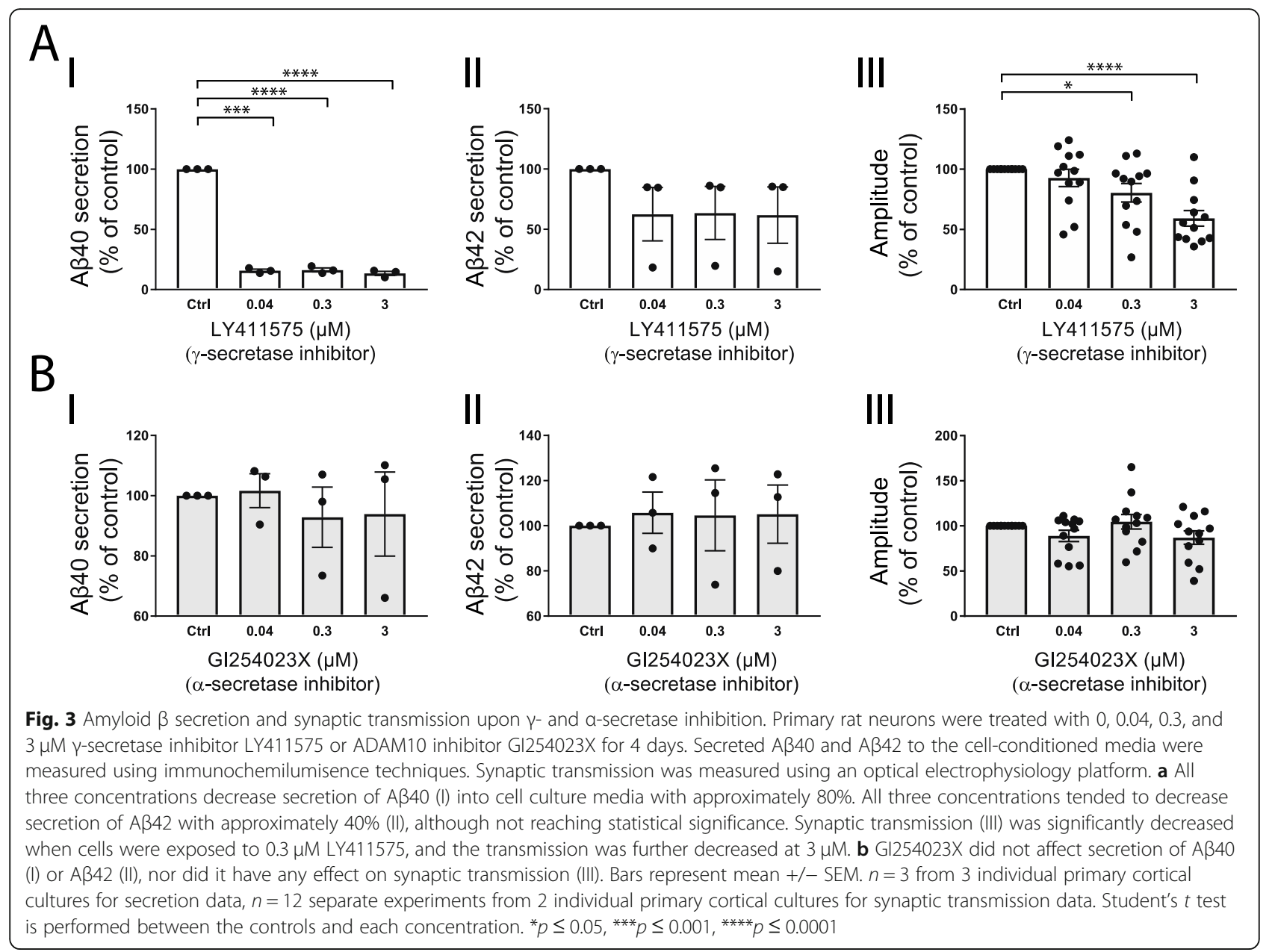

although not statistically significant, a trend towards decrease (about 37\%) in A $\beta 42$ secretion was observed at all concentrations (Fig. 3a (II)). While 0.04- $\mu$ M LY411575 treatment did not affect synaptic transmission, it significantly decreased synaptic transmission with $20 \%$ at $0.3 \mu \mathrm{M}$ (Fig. 3a (III)) and with $41 \%$ at $3 \mu \mathrm{M}$. The ADAM10 inhibitor GI254023X did not, as expected, affect secretion of A 340 (Fig. 3b (I)) or A 342 (Fig. 3b (II)), and no effect on synaptic transmission was observed (Fig. 3b (III)).

\section{Discussion}

So far, all clinical trials involving $\beta$-secretase inhibitors have been terminated due to side effects and/or lack of positive effects, and some studies even report cognitive decline possibly due to negative effects on putative physiological functions of APP and/or A $\beta$. Here, we evaluated the effects of three BACE inhibitors on $A \beta$ secretion and synaptic transmission, using electrochemiluminescent measurement techniques and an optical electrophysiology platform.

We found that negative effects of BACE inhibition on synaptic transmission did not correspond dose- dependently with decreased $A \beta$ secretion. Instead, all three inhibitors tested affected synaptic transmission negatively, but only at concentrations that decreased A 342 secretion by at least $50 \%$. For example, all concentrations of lanabecestat decreased the secretion of both $\mathrm{A} \beta 40$ and $\mathrm{A} \beta 42$ by more than $50 \%$ and, consistently, all concentrations of lanabecestat also decreased synaptic transmission. This is in concordance with previous publications showing that long-term exposure of high-dose BACE inhibitors reduced spine density in hippocampal neurons of mice [31, 32] and weakened synaptic transmission [31, 33].

The only concentration of LY2886721 that decreased synaptic transmission was the highest concentration of $3 \mu \mathrm{M}$. While all concentrations decreased A $\beta 40$ with $50 \%$ or more, $3 \mu \mathrm{M}$ was the only concentration of LY2886721 that decreased secretion of A $\beta 42$ with $50 \%$. This highlights the importance of future studies addressing possible links between A $\beta 42$ and synaptic transmission. Although it is difficult to compare in vivo doses to the in vitro equivalents, it is somewhat surprising that all three doses of lanabecestat resulted in the same, high 
levels of A $\beta$ inhibition. LY2886721 and lanabecestat were used at similar doses in the clinical trials (between 15 and $70 \mathrm{mg}$ daily for LY2886721 and 20 and $50 \mathrm{mg}$ daily for lanabecestat) with comparable effects on $A \beta$ reduction (between 50 and 70\% in CSF, depending on dose) [26].

BACE inhibitor IV decreased A $\beta$ secretion at all three concentrations, but only the highest concentration, decreasing $A \beta$ secretion by $60 \%$, affected synaptic transmission negatively. In fact, the lowest concentration with a mild effect on $\mathrm{A} \beta$ secretion ( $40 \%$ decrease) even increased synaptic transmission compared with control. These results are consistent with previous studies showing that $\mathrm{BACE}^{-/-}$mice have alterations in LTP [34] and hippocampus-dependent cognition [35] whereas $\mathrm{BACE}^{+/-}$ mice (only reducing BACE activity by $50 \%$ ) do not. Still, the fact that treatment with $0.3 \mu \mathrm{M}$ BACE inhibitor IV did not affect synaptic transmission, even though $A \beta$ levels were decreased by more than $50 \%$, shows that the effects of BACE inhibition on neuron communication is not only dependent on $A \beta$ levels, but also other factors may contribute. A relatively recent clinical trial conducted with a BACE inhibitor showed that inhibiting BACE increased sAPP $\alpha$ in CSF (ClinicalTrials.gov: NCT01827982 and NCT01887535) [36, 37], possibly as a results of more APP available as substrate for $\alpha$-secretase cleavage. SAPP $\alpha$ has been shown to be neuroprotective and to have positive impact on cognitive functions [38]. Although the reason behind the increased synaptic transmission by the lowest dose of BACE inhibitor IV in our study must be further investigated, moderate inhibition of BACE could potentially increase $\alpha$-cleavage and thus indirectly have a positive effect on synaptic activity. Additionally, BACE inhibitor IV is the only inhibitor tested here that is more selective to BACE1 than to BACE2 [27]. Hence, the increase in synaptic transmission with the lowest dose $(0.04 \mu \mathrm{M})$ could possibly also be a result of BACE inhibitor IV affecting BACE1 specifically while sparing BACE2 activity, although the BACE2 effect is unknown.

Although the $A \beta$ reduction could be responsible for at least some of the negative effects on synaptic transmission, BACE1 has several other substrates in addition to APP (reviewed in [39]), some of which are involved in dendritic spine dynamics, synaptic transmission, and memory formation [40], including the seizure-related gene 6 (SEZ6), close homolog of L1 (CHL1), and neuroligin 1 (NLGN1) proteins. Inhibiting BACE1 has been shown to reduce spine density in hippocampal neurons through SEZ6 [31, $32]$ and BACE null mice display axonal growth and myelination deficiencies, leading to abnormal or decreased synaptic transmission, due to altered cleavage of CHL1 and NLGN1 [41-43]. However, the alterations that are linked to SEZ6, CHL1, and NLGN1 proteins have been observed upon long-term inhibition of BACE1 or in BACE1 knockout mice [31, 32, 41-43]. In the current study, cells were treated with BACE inhibitors at a single occasion and the observations were made 4 days posttreatment in order to investigate if $A \beta$ can be reduced without affecting synaptic transmission. The involvement of other BACE substrates in altered synaptic transmission following short, low-dose BACE inhibition would be interesting to examine in future studies. In line with this, it would also be interesting to explore if combinations of low-dose BACE inhibitors could result in additive effects on $A \beta$ reduction without causing additive synaptic dysfunction.

Inhibition of $\gamma$-secretase using LY411575 decreased secretion of both $A \beta 40$ and $A \beta 42$ equally at all three doses, although the decrease of $A \beta 42$ did not reach statistical significance. The preferential inhibition of $A \beta 40$ over $A \beta 42$ has earlier been shown for other $\gamma$-secretase inhibitors, by our group and others $[44,45]$. This biased inhibition results in an increased $A \beta 42$ to $A \beta 40$ ratio, which is believed to be more amyloidogenic and could be negative for synaptic function [46]. Indeed, we saw a dose-dependent decrease in synaptic transmission upon treatment with the $\gamma$-secretase inhibitor LY411575. Inhibiting $\alpha$-secretase using GI254023X did not affect secretion of $\mathrm{A} \beta$ and had no effect on synaptic transmission.

\section{Conclusion}

In conclusion, we show that the optical electrophysiology platform is a suitable system to test possible side effects of drugs targeting neurodegeneration before reaching clinical trials and demonstrate that BACE inhibitor concentrations resulting in decreased $A \beta$ levels corresponding to the $\sim 30 \%$ reduction seen in carriers of the protective Icelandic mutation [12] do not affect synaptic transmission negatively. We therefore suggest that clinical studies should aim for a moderate central nervous system exposure of BACE inhibitors to avoid side effects caused by effects on synaptic efficacy.

\section{Abbreviations \\ Aß: Amyloid beta; AD: Alzheimer's disease; AMPA: a-Amino-3-hydroxy-5- methyl-4-isoxazolepropionic acid; APP: Amyloid beta precursor protein; BACE: Beta secretase; CHL1: Close homolog of L1; CSF: Cerebrospinal fluid; DIV: Days in vitro; EFS: Electric field stimulation; FAD: Familial Alzheimer's disease; LTP: Long-term potentiation; NLGN1: Neuroligin 1; NMDA: N-Methyl- d-aspartate; PET: Positron emission tomography; SEZ6: Seizure-related gene 6}

\section{Acknowledgements}

Not applicable

\section{Authors' contributions}

$H Z$, LA, and TS contributed to the study concept and design. TS, AK, SI, PK, and MK contributed to the acquisition and analysis of the data. TS, LA, HZ, and PB contributed to the interpretation of the data. LA and TS drafted the manuscript with substantial revision from $\mathrm{HZ}$ and $\mathrm{PB}$. All authors read and approved the final manuscript.

\section{Funding}

This work was supported by grants from the Knut and Alice Wallenberg Foundation, the Swedish Research Council (\#2018-02532), the European 
Research Council (\#681712), Swedish State Support for Clinical Research (\#ALFGBG-720931), the Alzheimer's Drug Discovery Foundation (ADDF), USA (\#201809-2016862), and Frimurarestiftelsen. The funding bodies had no role in the design of the study, data collection, analysis, interpretation, or writing of the manuscript

Open access funding provided by University of Gothenburg.

\section{Availability of data and materials}

The datasets used and/or analyzed during the current study are available from the corresponding author on reasonable request.

\section{Ethics approval and consent to participate}

All procedures for experiments were performed in accordance with the ethical committee in Gothenburg (ethical permit 5.8.18-11305/2018) and followed the guidelines of the Swedish National Board for Laboratory Animals.

\section{Consent for publication}

Not applicable.

\section{Competing interests}

$\mathrm{HZ}$ has served at scientific advisory boards for Samumed, CogRx, Roche Diagnostics, Denali, and Wave, has given lectures in symposia sponsored by Fujirebio, AlzeCure, and Biogen, and is a co-founder of Brain Biomarker Solutions in Gothenburg AB, a GU Ventures-based platform company at the University of Gothenburg. AK, MK, PK, and SI were all employed by Cellectricon $A B$ at the time for the experiments. All other authors declare that they have no competing interests.

\section{Author details}

${ }^{1}$ Institute of Neuroscience and Physiology, Department of Psychiatry and Neurochemistry, the Sahlgrenska Academy at the University of Gothenburg, S-415 30 Gothenburg, Sweden. ${ }^{2}$ Cellectricon AB, Neongatan 4B, S-431 53 Mölndal, Sweden. ${ }^{3}$ Institute of Neuroscience and Physiology, Department of Psychiatry and Neurochemistry, The Sahlgrenska Academy at the University of Gothenburg, S-431 80 Mölndal, Sweden. ${ }^{4}$ Clinical Neurochemistry Laboratory, Sahlgrenska University Hospital, S-431 80 Mölndal, Sweden. ${ }^{5}$ Department of Neurodegenerative Disease, Institute of Neurology, University College London Queen Square, WC1N 3BG, London, UK. ' UK Dementia Research Institute at UCL, WC1E 6BT, London, UK.

Received: 18 February 2020 Accepted: 18 May 2020

Published online: 26 May 2020

\section{References}

1. Winblad B, Amouyel P, Andrieu S, Ballard C, Brayne C, Brodaty H, et al. Defeating Alzheimer's disease and other dementias: a priority for European science and society. Lancet Neurol. 2016;15(5):455-532.

2. Hardy J, Allsop D. Amyloid deposition as the central event in the aetiology of Alzheimer's disease. Trends Pharmacol Sci. 1991;12(10):383-8.

3. Selkoe DJ, Hardy J. The amyloid hypothesis of Alzheimer's disease at 25 years. EMBO Mol Med. 2016;8(6):595-608.

4. Portelius E, Price E, Brinkmalm G, Stiteler M, Olsson M, Persson R, et al. A novel pathway for amyloid precursor protein processing. Neurobiol Aging. 2011;32(6):1090-8.

5. Mangialasche F, Solomon A, Winblad B, Mecocci P, Kivipelto M. Alzheimer's disease: clinical trials and drug development. Lancet Neurol. 2010;9(7):70216.

6. Blennow K, Zetterberg H, Haass C, Finucane T. Semagacestat's fall: where next for AD therapies? Nat Med. 2013;19(10):1214-5.

7. Li R, Lindholm K, Yang L-B, Yue X, Citron M, Yan R, et al. Amyloid $\beta$ peptide load is correlated with increased $\beta$-secretase activity in sporadic Alzheimer's disease patients. Proc Natl Acad Sci U S A. 2004;101(10):3632-7.

8. Fukumoto $\mathrm{H}$, Rosene DL, Moss MB, Raju S, Hyman BT, Irizarry MC. $\beta$ Secretase activity increases with aging in human, monkey, and mouse brain. Am J Pathol. 2004;164(2):719-25.

9. Zetterberg $H$, Andreasson U, Hansson O, Wu G, Sankaranarayanan S, Andersson $\mathrm{ME}$, et al. Elevated cerebrospinal fluid BACE1 activity in incipient Alzheimer disease. Arch Neurol. 2008;65(8):1102-7.
10. Haass C, Lemere CA, Capell A, Citron M, Seubert P, Schenk D, et al. The Swedish mutation causes early-onset Alzheimer's disease by $\beta$-secretase cleavage within the secretory pathway. Nat Med. 1995;1(12):1291-6.

11. Jonsson T, Atwal JK, Steinberg S, Snaedal J, Jonsson PV, Bjornsson S, et al. A mutation in APP protects against Alzheimer's disease and age-related cognitive decline. Nature. 2012:488(7409):96-9.

12. Martiskainen $H$, Herukka S-K, Stančáková A, Paananen J, Soininen H, Kuusisto J, et al. Decreased plasma $\beta$-amyloid in the Alzheimer's disease APP A673T variant carriers. Ann Neurol. 2017;82(1):128-32.

13. Forman M, Palcza J, Tseng J, Leempoels J, Ramael S, Han D, et al. The novel BACE inhibitor MK-8931 dramatically lowers cerebrospinal fluid A $\beta$ peptides in healthy subjects following single- and multiple-dose administration. Alzheimers Dement. 2012;8(4):P704.

14. Zhu K, Peters F, Filser S, Herms J. Consequences of pharmacological BACE inhibition on synaptic structure and function. Biol Psychiatry. 2018;84(7): 478-87

15. Haass C, Schlossmacher MG, Hung AY, Vigo-Pelfrey C, Mellon A, Ostaszewsk $\mathrm{BL}$, et al. Amyloid $\beta$-peptide is produced by cultured cells during normal metabolism. Nature. 1992:359(6393):322-5.

16. Luo Y, Sunderland T, Roth GS, Wolozin B. Physiological levels of $\beta$-amyloid peptide promote PC12 cell proliferation. Neurosci Lett. 1996;217(2):125-8.

17. Chen $Y$, Dong C. A 340 promotes neuronal cell fate in neural progenitor cells. Cell Death Differ. 2009;16(3):386-94.

18. Kamenetz F, Tomita T, Hsieh H, Seabrook G, Borchelt D, Iwatsubo T, et al. APP processing and synaptic function. Neuron. 2003;37(6):925-37.

19. Morley JE, Farr SA, Banks WA, Johnson SN, Yamada KA, Xu L. A physiological role for amyloid-beta protein:enhancement of learning and memory. J Alzheimers Dis. 2010;19(2):441-9.

20. Sidders B, Karlsson A, Kitching L, Torella R, Karila P, Phelan A. Network-based drug discovery: coupling network pharmacology with phenotypic screening for neuronal excitability. J Mol Biol. 2018;430(18, Part A):3005-15.

21. Chan B, Cottrell JR, Li B, Larson KC, Ashford CJ, Levenson JM, et al. Development of a high-throughput AlphaScreen assay for modulators of synapsin I phosphorylation in primary neurons. J Biomol Screen. 2014;19(2):205-14

22. Mattsson N, Rajendran L, Zetterberg H, Gustavsson M, Andreasson U, Olsson $M$, et al. BACE1 inhibition induces a specific cerebrospinal fluid $\beta$-amyloid pattern that identifies drug effects in the central nervous system. PLoS One. 2012;7(2):e31084.

23. May PC, Willis BA, Lowe SL, Dean RA, Monk SA, Cocke PJ, et al. The potent BACE1 inhibitor LY2886721 elicits robust central Abeta pharmacodynamic responses in mice, dogs, and humans. J Neurosci. 2015;35(3):1199-210.

24. Lahiri DK, Maloney B, Long JM, Greig NH. Lessons from a BACE1 inhibitor trial: off-site but not off base. Alzheimer's Dementia. 2014;10(5, Supplement): S411-9.

25. Sakamoto K, Matsuki S, Matsuguma K, Yoshihara T, Uchida N, Azuma F, et al. BACE1 inhibitor lanabecestat (AZD3293) in a phase 1 study of healthy Japanese subjects: pharmacokinetics and effects on plasma and cerebrospinal fluid Abeta peptides. J Clin Pharmacol. 2017;57(11):1460-71.

26. Wessels AM, Tariot PN, Zimmer JA, Selzler KJ, Bragg SM, Andersen SW, et al. Efficacy and safety of lanabecestat for treatment of early and mild Alzheimer disease: the AMARANTH and DAYBREAK-ALZ randomized clinical trials. JAMA Neurol. 2019;77(2):199-209.

27. Stachel SJ, Coburn CA, Steele TG, Jones KG, Loutzenhiser EF, Gregro AR, et al. Structure-based design of potent and selective cell-permeable inhibitors of human beta-secretase (BACE-1). J Med Chem. 2004;47(26): 6447-50.

28. Neff R, Lindwall-Blom C, Jägervall $\AA$, Balana B, Karlsson M, Karila P, et al., Development of a moderate throughput assay to detect novel modulators of synaptic efficacy in neuronal cultures in Society for Neuroscience 2015: Washington, DC

29. Willem M, Tahirovic S, Busche MA, Ovsepian SV, Chafai M, Kootar S, et al. Eta-Secretase processing of APP inhibits neuronal activity in the hippocampus. Nature. 2015;526(7573):443-7.

30. Imbimbo BP, Watling M. Investigational BACE inhibitors for the treatment of Alzheimer's disease. Expert Opin Investig Drugs. 2019;28(11):967-75.

31. Filser S, Ovsepian SV, Masana M, Blazquez-Llorca L, Brandt Elvang A, Volbracht C, et al. Pharmacological inhibition of BACE1 impairs synaptic plasticity and cognitive functions. Biol Psychiatry. 2015;77(8):729-39.

32. Zhu K, Xiang X, Filser S, Marinković P, Dorostkar MM, Crux S, et al. Beta-site amyloid precursor protein cleaving enzyme 1 inhibition impairs synaptic plasticity via seizure protein 6. Biol Psychiatry. 2018;83(5):428-37. 
33. Kamikubo Y, Takasugi N, Niisato K, Hashimoto Y, Sakurai T. Consecutive analysis of BACE1 function on developing and developed neuronal cells. J Alzheimer's Disease. 2017;56(2):641-53.

34. Wang H, Megill A, Wong PC, Kirkwood A, Lee H-K. Postsynaptic target specific synaptic dysfunctions in the CA3 area of BACE1 knockout mice. PLoS One. 2014;9(3):e92279.

35. Laird FM, Cai H, Savonenko AV, Farah MH, He K, Melnikova T, et al. BACE1, a major determinant of selective vulnerability of the brain to amyloid- $\beta$ amyloidogenesis, is essential for cognitive, emotional, and synaptic functions. J Neurosci. 2005;25(50):11693-709.

36. Timmers M, Van Broeck B, Ramael S, Slemmon J, De Waepenaert K, Russu A, et al. Profiling the dynamics of CSF and plasma $A \beta$ reduction after treatment with JNJ-54861911, a potent oral BACE inhibitor. Alzheimers Dement. 2016;2(3):202-12.

37. Roberts SB, Ripellino JA, Ingalls KM, Robakis NK, Felsenstein KM. Nonamyloidogenic cleavage of the beta-amyloid precursor protein by an integral membrane metalloendopeptidase. J Biol Chem. 1994;269(4):3111-6.

38. Mockett BG, Richter M, Abraham WC, and Müller UC. Therapeutic potential of secreted amyloid precursor protein APPsa. Front Molecular Neurosci. 2017;10(30):1-14. https://doi.org/10.3389/fnmol.2017.00030 eCollection 2017.

39. Vassar R, Kovacs DM, Yan R, Wong PC. The $\beta$-secretase enzyme BACE in health and Alzheimer's disease: regulation, cell biology, function, and therapeutic potential. J Neurosci. 2009;29(41):12787-94.

40. Das B, Yan R. Role of BACE1 in Alzheimer's synaptic function. Trans Neurodegener. 2017;6:23.

41. Hitt B, Riordan SM, Kukreja L, Eimer WA, Rajapaksha TW, Vassar R. B-Site amyloid precursor protein (APP)-cleaving enzyme 1 (BACE1)-deficient mice exhibit a close homolog of L1 (CHL1) loss-of-function phenotype involving axon guidance defects. J Biol Chem. 2012;287(46):38408-25.

42. Willem M, Lammich $S$, Haass C. Function, regulation and therapeutic properties of $\beta$-secretase (BACE1). Semin Cell Dev Biol. 2009;20(2):175-82.

43. Fleck D, Garratt AN, Haass C, Willem M. BACE1 dependent neuregulin processing: review. Curr Alzheimer Res. 2012;9(2):178-83.

44. Agholme L, Clarin M, Gkanatsiou E, Kettunen P, Chebli J, Brinkmalm G, et al. Low-dose gamma-secretase inhibition increases secretion of Abeta peptides and intracellular oligomeric Abeta. Mol Cell Neurosci. 2017;85:211-9.

45. Lanz TA, Karmilowicz MJ, Wood KM, Pozdnyakov N, Du P, Piotrowski MA et al. Concentration-dependent modulation of amyloid-beta in vivo and in vitro using the gamma-secretase inhibitor, LY-450139. J Pharmacol Exp Ther. 2006;319(2):924-33.

46. Lacor PN, Buniel MC, Furlow PW, Clemente AS, Velasco PT, Wood M, et al. Abeta oligomer-induced aberrations in synapse composition, shape, and density provide a molecular basis for loss of connectivity in Alzheimer's disease. J Neurosci. 2007:27(4):796-807.

\section{Publisher's Note}

Springer Nature remains neutral with regard to jurisdictional claims in published maps and institutional affiliations.

Ready to submit your research? Choose BMC and benefit from:

- fast, convenient online submission

- thorough peer review by experienced researchers in your field

- rapid publication on acceptance

- support for research data, including large and complex data types

- gold Open Access which fosters wider collaboration and increased citations

- maximum visibility for your research: over $100 \mathrm{M}$ website views per year

At BMC, research is always in progress.

Learn more biomedcentral.com/submissions 